\title{
Оптические свойства наночастиц CdSe/ZnS в пленках термообработанного поливинилхлорида
}

\author{
(C) С.И. Расмагин ${ }^{1}$, И.К. Новиков ${ }^{2}$ \\ ${ }^{1}$ Институт общей фризики им. А.М. Прохорова Российской академии наук, \\ 119991 Москва, Россия \\ ${ }^{2}$ Национальный исследовательский ядерный университет „МИФИ“, \\ 115409 Москва, Россия \\ E-mail: rasmas123@yandex.ru
}

(Получена 29 октября 2018 г.

Принята к печати 5 ноября 2018 г.

Принята к публикации 5 ноября 2018 г.)

Получены композиты на основе поливинилхлорида с внедренными наночастицами CdSe $\mathrm{ZnS}$. Проведены исследования оптических и электрофизических свойств созданных полимерных композитов с наночастицами $\mathrm{CdSe} / \mathrm{ZnS}$. Измерены спектры поглощения и фотолюминесценции, а также объемные удельные сопротивления полученных композитов. Определены размеры наночастиц CdSe. Установлено, что при термообработке с небольшим временем интенсивность фотолюминесценции увеличивается, а при нагреве с большим временем значительно уменьшается.

DOI: 10.21883/FTP.2019.04.47450.9016

\section{1. Введение}

Полупроводниковые наночастицы (квантовые точки) нашли широкое применение в оптике, оптоэлектронике, медицине и биологии. В частности, в последнее время интенсивно исследуются оптические свойства наночастиц CdSe как в растворах (неорганические и органические растворители), так и в различных пленках [1-4]. Полупроводниковые наночастицы $\mathrm{CdSe}$, распределенные в пленках, по сравнению с полупроводниковыми наночастицами в растворах имеют большее практические применения. Это вызвано тем, что для получения пленок используются простые и недорогие технологии. В частности, в настоящее время квантовые точки используются в органических полупроводниках [5]. Благодаря квантово-размерному эффекту наночастицы полупроводников способны люминесцировать в широком оптическом диапазоне при возбуждении излучением с одной длиной волны. Положение пика фотолюминесценции и границу поглощения можно регулировать путем изменения размеров наночастиц $\mathrm{CdSe}$. Наночастицы $\mathrm{CdSe}$ должны быть защищены от вредного воздействия окружающей среды, максимально изолированы друг от друга и иметь высокую эффективность фотолюминесценции. Для выполнения этих условий необходимо создать нанокомпозит $\mathrm{CdSe} / \mathrm{ZnS}$ (селенид кадмия/сульфид цинка) с внешней оболочкой ТОРО (trioctylphosphine) и внедрять его в полимерные матрицы. Наночастицы CdSe покрывают наночастицами $\mathrm{ZnS}$ для увеличения квантового выхода фотолюминесценции, который может достигать значения 50\% [6]. Полимерные композиты важны для применения полупроводниковых наночастиц $\mathrm{CdSe} / \mathrm{ZnS}$ в электролюминесцентных устройствах (композиты с проводящими полимерами, в нашем случае это термообработанные пленки поливинилхлорида) и в оптических материалах (композиты с прозрачными полимерами, в частности с чистым поливинилхлоридом, без термообработки). Целью данной работы было получение и исследование оптических свойств полупроводниковых наночастиц $\mathrm{CdSe} / \mathrm{ZnS}$, распределенных в пленках чистого поливинилхлорида (ПВХ), полученных в разных растворителях и пленках, подвергшихся термообработке при разных температурах.

\section{2. Экспериментальная часть}

Для получения ядра и оболочки квантовой точки $\mathrm{CdSe} / \mathrm{ZnS}$ используется двухэтапная процедура синтеза. На первом этапе синтезируются почти монодисперсные нанокристаллиты $\mathrm{CdSe}$ посредством высокотемпературного роста из коллоидного раствора диметилкадмия и триоктилфосфин селенида, за которым следует размерно-селективное осаждение, т.е. осаждение методом центрифугирования частиц определенного размера. Размеры полученных частиц колеблются в пределах от 23 до $55 \AA$ А, эти квантовые точки называются „безоболочечными“, хотя большая часть их поверхности пассивирована органической группой ТОРО. Далее, наночастицы CdSe, помещенные в $\mathrm{TOPO}$ при средних температурах, покрываются оболочкой посредством добавки промежуточных соединений, содержащих $\mathrm{Zn}$ и $\mathrm{S}$. Большая часть поверхности полученных наночастиц $\mathrm{CdSe} / \mathrm{ZnS}$ также пассивирована TOРО. Наночастицы $\mathrm{CdSe} / \mathrm{ZnS}$, пассированные ТОРО, были в виде красного порошка. Для получения термообработанных пленок ПВХ в качестве исходного материала использовали чистый ПВХ марки С-7058M. В пробирке растворили порошок (гранулы) ПВХ в соотношении: в 100 мл ацетофенона 4г ПВХ. Затем пробирку с полученным 
раствором поместили в термостат. В термостате проводили процесс термолиза при температуре $190^{\circ} \mathrm{C}$ в течение 40 и 520 мин, более подробно описанный в $[7,8]$. В результате получили термообработанные растворы объемом 1 мл, в которые добавили порошок нанокомпозитов $\mathrm{CdSe} / \mathrm{ZnS}$ в количестве 10 мг. Для создания пленок полученные растворы заливали в чашки Петри диаметром $d=3.5 \mathrm{~cm}$ и подвергали сушке при $95^{\circ} \mathrm{C}$ в течение 48 ч. В результате получили пленки ПВХ c внедренным нанокомпозитом $\mathrm{CdSe} / \mathrm{ZnS}$ (композит $\mathrm{CdSe} / \mathrm{ZnS}-\mathrm{PVC}$ ) с разным временем термообработки. Исходные пленки получали из растворов ПВХ в растворителях ацетофенон и тетрагидрофуран. Группа полученных образцов, включая чистый ПВХ марки С$7058 \mathrm{M}$, имеет толщину $\sim 30$ мкм. Спектры поглощения и фотолюминесценции нанокомпозитов $\mathrm{CdSe} / \mathrm{ZnS}$ в полимерной матрице были измерены на спектрометре Ocean Optics 2000. В качестве источников использовали соответственно вольфрамовую лампу и светодиод с максимумом спектра при 365 нм. Размер наночастиц $\mathrm{CdSe}$ определялся по данным просвечивающей электронной микроскопии (ПЭМ) и спектрам поглощения. Сопротивление композитных пленок $\mathrm{CdSe} / \mathrm{ZnS}-\mathrm{PVC}$ измерялось тераомметром Е6-3.

\section{3. Результаты и их обсуждение}

На рис. 1 представлена микрофотография наночастиц CdSe. Из рис. 1 видно, что частицы имеют сферическую или квазисферическую форму, диаметр 10-12 нм.

На рис. 2 представлены спектры поглощения композитных пленок $\mathrm{CdSe} / \mathrm{ZnS}-\mathrm{PVC}$, измеренные при температуре $24^{\circ} \mathrm{C}$. Можно обнаружить две особенности, с энергиями 1.98 и 2.42 эВ.

Они смещены в область коротких волн по отношению к ширине запрещенной зоны 1.74 эВ объемного полупроводника $\mathrm{CdSe}$, и смещение хорошо согласуется

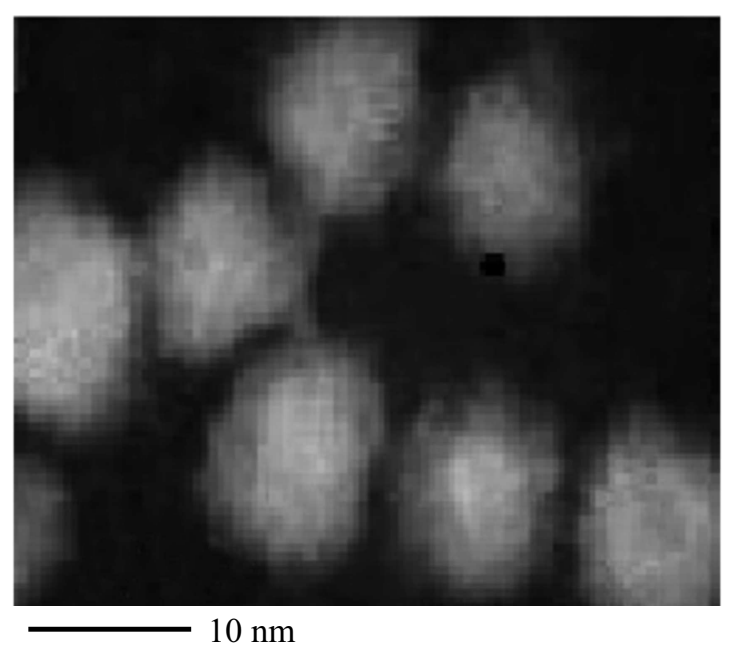

Pис. 1. ПЭМ-микрофотография наночастиц CdSe.

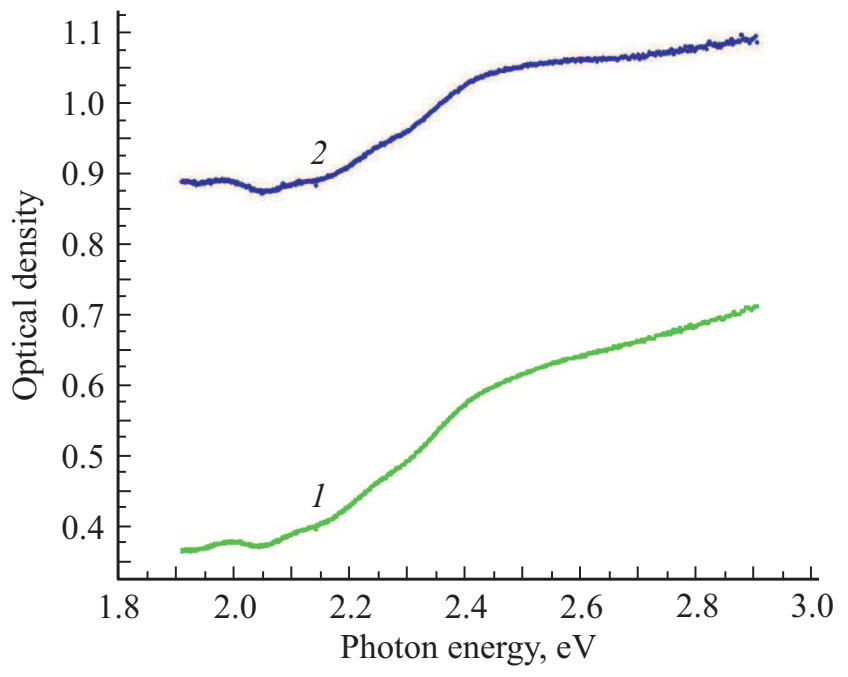

Рис. 2. Спектры поглощения пленок композита $\mathrm{CdSe} / \mathrm{ZnS}-$ $\mathrm{PVC}$, полученных при термообработке в течение 40 мин (1), 520 мин (2).

с теорией [9]. Для промежуточного размерного квантования $a_{h}<r<a_{e}$, где $a_{h}=3 \mathrm{Hм}-$ боровский радиус дырки, $a_{e}=13$ нм - боровский радиус электрона, $r=5-6$ нм - радиус наночастицы. При изменении радиуса наночастицы $\mathrm{CdSe}$ линии в спектрах поглощения сдвигаются в соответствии с выражением

$$
\hbar \omega_{l, n}=E_{g}+\frac{\hbar^{2}}{2 m^{*} r^{2}} \varphi_{l, n}^{2},
$$

где $E_{g}=1.74$ эВ - ширина запрещенной зоны объемного полупроводника $\mathrm{CdSe}, m^{*}=\left(m_{e} m_{h}\right) /\left(m_{e}+m_{h}\right), m_{e}$ и $m_{h}$ - эффективные массы электронов и дырок в $\mathrm{CdSe}, \varphi_{0,1}=3.14$ (безразмерный коэффициент), кулоновское взаимодействие между электроном и дыркой и взаимодействие электрона и дырки с поверхностью наночастицы CdSe незначительны. Край поглощения определяется переходами между первыми уровнями размерного квантования электронов и дырок и сдвигается обратно пропорционально квадрату радиуса наночастицы в область больших энергий. Из формулы (1) были рассчитаны средние радиусы наночастиц CdSe: поглощению с энергией 1.9 эВ соответствуют наночастицы $\mathrm{CdSe}$ с радиусом 9 нм, а поглощению с энергией 2.42 эВ наночастицы $\mathrm{CdSe}$ с радиусом 5 нм. Итак, расчетные и экспериментальные значения средних радиусов наночастиц CdSe близки по своим значениям.

На рис. 3 показан спектр фотолюминесценции порошкового нанокомпозита $\mathrm{CdSe} / \mathrm{ZnS}$.

Видно, что максимум спектра фотолюминесценции наночастицы $\mathrm{CdSe} / \mathrm{ZnS}$ соответствует длине волны $\lambda_{m s p}=630 \mathrm{Hм}[10]$ и сдвинут относительно максимума спектра объемного полупроводника на 82 нм благодаря размерному квантованию. Так как максимум длины волны фотолюминесценции соответствует энергии рекомбинации электронно-дырочных пар, энергия рекомбинации 


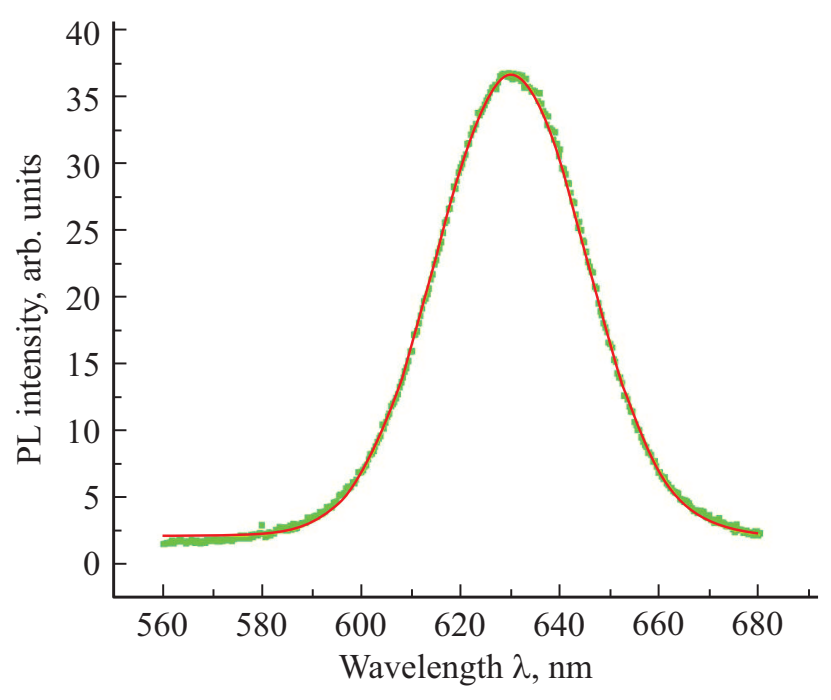

Рис. 3. Спектр фотолюминесценции (PL) порошка наночастиц $\mathrm{CdSe} / \mathrm{ZnS}$.

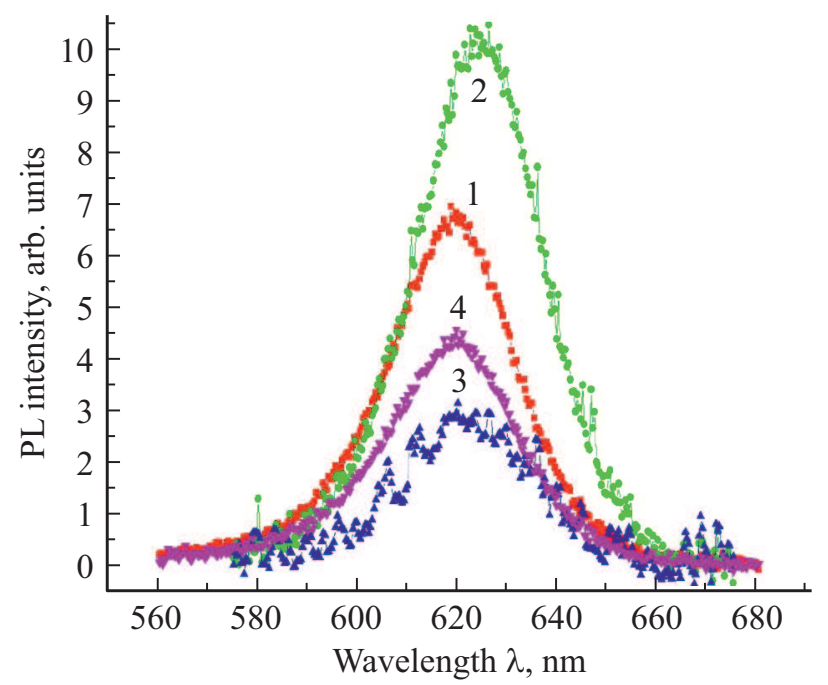

Рис. 4. Спектры фотолюминесценции композитов $\mathrm{CdSe} / \mathrm{ZnS}-$ PVC: 1 - чистая пленка ПВХ (тетрагидрофуран), 2 - термообработка ПВХ 40 мин, 3 - термообработка ПВХ 520 мин, 4 - чистая пленка ПВХ (ацетофенон).

будет $\sim 1.98$ эВ. Используя данное смещение и соотношение (1), рассчитали средний радиус наночастиц CdSe, оказавшийся равным 8 нм. Полученный средний радиус по-прежнему удовлетворяет промежуточному размерному квантованию. Полуширина спектра фотолюминесценции составила $\Delta \lambda=30 \mathrm{Hм}$.

На рис. 4 показаны спектры фотолюминесценции композитных пленок $\mathrm{CdSe} / \mathrm{ZnS}-\mathrm{PVC}$, полученные при температуре $24^{\circ} \mathrm{C}$.

Анализируя рис. 4, видим, что происходит сдвиг спектров в коротковолновую область по сравнению с объемным полупроводником на 93 нм и по сравнению с порошком $\mathrm{CdSe} / \mathrm{ZnS}$ на 11 нм благодаря размерному квантованию. Максимумы спектра фотолюминесцен- ции для композитов $\mathrm{CdSe} / \mathrm{ZnS}-\mathrm{PVC}$ (пленка чистого ПВХ, полученного в тетрагидрофуране, образец 1) и $\mathrm{CdSe} / \mathrm{ZnS}-\mathrm{PVC}$ (пленка чистого ПВХ, полученного в ацетофеноне, образец 4) совпадают и соответствуют 619 нм. Можно предположить, что на энергетические уровни нанокомпозита $\mathrm{CdSe} / \mathrm{ZnS}$ в ПВХ природа растворителя не оказывает влияния. Похожий результат обнаружен в других растворителях (толуоле и воде) в работе [11]. Что касается интенсивности фотолюминесценции, то она больше в 1.8 раза в образце 1 по сравнению с образцом 4 из-за меньшего поглощения излучения в тетрагидрофуране.

Для образца 2 (термообработка 40мин) максимум спектра фотолюминесценции соответствует $\lambda=626 \mathrm{Hм}$ (1.98 эВ). Полуширина спектра фотолюминесценции составляет $\Delta \lambda=30$ нм. Коротковолновый сдвиг спектра фотолюминесценции образца 2 по отношению к спектру порошка $\mathrm{CdSe} / \mathrm{ZnS}-\mathrm{PVC}$ незначителен, составляет всего 4 нм. Иными словами, корректировка спектра фотолюминесценции в результате термообработки в течение 40 мин незначительна. Однако интенсивность фотолюминесценции образца 2 в 1.5 раза выше, чем образца 1. Можно предположить, что термообработка композита $\mathrm{CdSe} / \mathrm{ZnS}-\mathrm{PVC}$ при $190^{\circ} \mathrm{C}$ в течение 40 мин приводит к диспергированию наночастиц $\mathrm{CdSe} / \mathrm{ZnS}$, соответственно росту их концентрации и увеличению интенсивности фотолюминесценции.

Для образца 3 (термообработка 520 мин) максимум спектра фотолюминесценции соответствует $\lambda=623 \mathrm{Hм}$ (1.99 эВ). Полуширина спектра фотолюминесценции составляет $\Delta \lambda=30$ нм. Коротковолновый сдвиг спектра фотолюминесценции составляет 7 нм. Интенсивность фотолюминесценции образца 3 уменьшилась в 2.3 раза по сравнению с образцом 1. Это можно объяснить созданием двойных сопряженных связей углерода в ПВХ в результате термообработки в течение 520 мин и сильным поглощением фотолюминесценции в диапазоне 620-640 нм. Итак, для всех пленок 1-4 полуширина спектра фотолюминесценции составила $\Delta \lambda \approx 30$ нм. Этот факт свидетельствует о слабом влиянии растворителей и полимерной матрицы на наночастицы $\mathrm{CdSe} / \mathrm{ZnS}$. Для композитных пленок $\mathrm{CdSe} / \mathrm{ZnS}-\mathrm{PVC}$ были также измерены удельные сопротивления при температуре $24^{\circ} \mathrm{C}$. Техника эксперимента и методика измерения удельного сопротивления подробно описаны в работах [12,13]. Для образцов 2 и 3 удельное сопротивление составило соответственно $\rho \sim 10^{7}$ и 800 Ом · см. Удельное сопротивление образца 3 уменьшилось на 12 порядков по сравнению с исходным композитом (образец 1 , удельное сопротивление $10^{15} \mathrm{OM} \cdot \mathrm{cm}$ ) благодаря созданию двойных сопряженных связей углерода и внутреннему допированию атомами хлора [14]. При этом максимум интенсивности фотолюминесценции образца 3 по сравнению с образцом 2 меньше в 3.6 раза. Таким образом, можно получить либо композит $\mathrm{CdSe} / \mathrm{ZnS}-\mathrm{PVC}$ с большим удельным сопротивлением и большой интенсивностью фотолюминесценции, либо 
композит $\mathrm{CdSe} / \mathrm{ZnS}-\mathrm{PVC}$ с малым удельным сопротивлением и малой интенсивностью фотолюминесценции. Тем не менее полученный образец 3 имеет практический интерес. Его можно использовать, например, в солнечных элементах в качестве полупроводника $p$-типа проводимости. Добавление наночастиц $\mathrm{CdSe} / \mathrm{ZnS}$ в полимер с двойными сопряженными связями углерода может дать увеличение эффективности преобразования энергии в солнечной батарее.

\section{4. Заключение}

В результате проведенной работы по анализу оптических и электрофизических свойств полимерных композитов $\mathrm{CdSe} / \mathrm{ZnS}-\mathrm{PVC}$, прошедших термообработку и без нее, приходим к следующим выводам.

- Интенсивность фотолюминесценции полимерного композита $\mathrm{CdSe} / \mathrm{ZnS}-\mathrm{PVC}$ при небольших временах термообработки увеличивается в 1.5 раза по сравнению с композитом чистого ПВХ. При этом удельное сопротивление композита $\mathrm{CdSe} / \mathrm{ZnS}-\mathrm{PVC}$, хотя и сильно уменьшается, но все же остается очень высоким, $\sim 10^{7} \mathrm{OM} \cdot \mathrm{cм}$, и дает возможность получить диэлектрический полимер с интенсивной фотолюминесценцией.

- Интенсивность фотолюминесценции полимерного композита $\mathrm{CdSe} / \mathrm{ZnS}-\mathrm{PVC}$ при больших временах термообработки, напротив, уменьшается в 2.8 раза по сравнению с композитом на основе чистого ПВХ CdSe/ZnS-PVC. При этом удельное сопротивление композита значительно уменьшается, до величины 800 Ом · см. Таким образом можно получить фотолюминесцентный полупроводник $p$-типа проводимости.

- Коротковолновый сдвиг максимума фотолюминесценции наночастиц $\mathrm{CdSe}$ в композите незначителен, 4-7 нм, как при малых, так и при больших временах термообработки.

\section{Список литературы}

[1] А.К. Вишератина., А.О. Орлова, В.Г. Маслов, А.В. Федоров, А.В. Баранов. Оптич. журн., 82 (11), 30 (2015).

[2] А.С. Кулагина, В.В. Данилов, В.Б. Шилов, К.М. Григоренко, В.В. Власов, Г.М. Ермолаева. Опт. и спектр., 123 (1), 152 (2017).

[3] А.И. Аржанов, К.Р. Каримуллин, А.В. Наумов. В кн.: XI Междунар. симп. по ботонному эхо и когерентной спектроскопии (ФЭКС-2017). Сб. тезисов (2017) с. 151.

[4] А.В. Заседателев, В.А. Кривенков, И.Л. Мартынов. Изв. Самарского научного центра РАН, 15 (4-1), 108 (2013).

[5] J. Zhao, J.A. Bardecker, A.M. Munro, M.S. Liu, Y. Niu, I.-K. Ding, J. Luo, B. Chen, A.K.-Y. Jen, D.S. Ginger. Nano Lett., 6 (3), 463 (2006).

[6] B.O. Dabbousi, J. Rodriguez-Viejo, F.V. Mikulec et al. J. Phys. Chem. B, 101, 9463 (1997).

[7] В.И. Крыштоб, С.И. Расмагин. ЖТФ, 87 (11), 1687 (2017). DOI: 10.21883/JTF.2017.11.45130.1907
[8] И.К. Новиков, В.И. Крыштоб, С.И. Расмагин. Прикл. физика, № 5, 70 (2017).

[9] Ал.Л. Эфрос, А.Л. Эфрос. ФТП, 16 (7), 1209 (1982).

[10] Л.И. Гуринович, А.А. Лютич, А.П. Ступак, С.Я. Прислопский, Е.К. Русаков, М.В. Артемьев, С.В. Гапоненко, Х.В. Демир. ФТП, 43 (8), 1045 (2009).

[11] Е.С. Сперанская, В.В. Гофтман, А.О. Дмитриенко, В.П. Дмитриенко, Т.А. Акмаева, Д.В. Потапкин, И.Ю. Горячева. Изв. Саратовского ун-та. Нов. сер. Сер. Химия. Биология. Экология, 12 (4), 3 (2012).

[12] S.I. Rasmagin, V.I. Krasovskii, I.K. Novikov, V.I. Krystob, I.N. Feofanov. Proc. SPIE, 10614 [Intern. Conf. on Atomic and Molecular Pulsed Lasers XIII, 106140B (2018)]. DOI: $10.1117 / 12.2302981$

[13] В.И. Крыштоб, Д.В. Власов, В.Ф. Миронов, Л.А. Апресян, Т.В. Власова, С.И. Расмагин, 3.А. Кураташвили, А.А. Соловский. Электротехника, № 8, 39 (2015).

[14] И.К. Новиков, В.И. Крыштоб, С.И. Расмагин. Прикл. физика, №5, 70 (2017).

Редактор Л.В. Шаронова

\section{Optical properties of $\mathrm{CdSe} / \mathrm{ZnS}$ nanoparticles in films of heat-treated polyvinyl chloride}

\author{
S.I. Rasmagin ${ }^{1}$, I.K. Novikov ${ }^{2}$ \\ ${ }^{1}$ Prokhorov General Physics Institute, \\ 119991 Moscow, Russia \\ ${ }^{2}$ National Research Nuclear University „MEPhl“, \\ 115409 Moscow, Russia
}

\begin{abstract}
Composites based on polyvinyl chloride and $\mathrm{CdSe} / \mathrm{ZnS}$ nanoparticles embedded in it were obtained. The optical and electrophysical properties of the created polymer composites with $\mathrm{CdSe} / \mathrm{ZnS}$ nanoparticles have been studied. Absorption and photoluminescence spectra, as well as volume resistivities of the composites were measured. The sizes of CdSe nanoparticles were determined. It was found that during heat treatment with a short time, the intensity of the photoluminescence increases, and when heated with a long time, it decreases significantly.
\end{abstract}

